\title{
REDESIGN E GAMIFICAÇÃO DE SISTEMA DE LEVANTAMENTO DE NECESSIDADES DE CAPACITAÇÃO NO ÂMBITO DA GESTÃO DE PESSOAS DE UMA UNIVERSIDADE FEDERAL
}

\author{
REDESIGN AND GAMIFICATION OF A TRAINING NEEDS SURVEY \\ SYSTEM IN HUMAN RESOURCES MANAGEMENT OF A FEDERAL \\ UNIVERSITY
}

\author{
Ruth Praxedes de Paiva Veras ${ }^{1}$, M.Sc. \\ José Guilherme da Silva Santa Rosa², D.Sc. \\ (1) Universidade Federal do Rio Grande do Norte \\ e-mail: ruthpraxedes@gmail.com \\ (2) Universidade Federal do Rio Grande do Norte \\ e-mail: jguilhermesantarosa@gmail.com
}

Design Centrado no Usuário, Gamificação, Experiência do Usuário

\begin{abstract}
O presente artigo apresenta e discute os procedimentos e os resultados do processo de Redesign do Sistema de Levantamento de Necessidades de Capacitação da Universidade Federal do Rio Grande do Norte a partir da abordagem do Design Centrado no Usuário e da Gamificação. Foram realizadas entrevistas e Avaliações Cooperativas e aplicado Questionário de Satisfação a respeito da percepção dos usuários sobre a versão antiga e a versão redesenhada do sistema. A técnica de Avaliação Cooperativa foi associada a Observação Sistemática por análise da Tarefa, tarefas essas descritas em listas de tarefas desenvolvidas para cada perfil entrevistado (docente, gestor e técnico-adminsitrativo). De modo geral, a nova versão, redesenhada e gamificada, aumentou a aceitação e o engajamento dos usuários-servidores no processo de preenchimento pelo sistema e apresentou quantidade menor de falhas de usabilidade em sua interface. A maioria dos usuários aprovou a mudança e percebeu-se que Gamificação e DCU colaboraram para esse resultado, embora a pesquisa mostre vários pontos no sistema que ainda necessitam de aprimoramento.
\end{abstract}

\section{User Centred Design, Gamification, User Experience}

This paper presents and discuss the proceedings and results from redesign process of the Federal University of Rio Grande do Norte's Training Needs Survey System, from the User Centred Design (UCD) and Gamification approach . It were done interviews and cooperative evaluates and it was applicated a satisfaction questionary - QUIS with users. The Cooperative Evaluation Technic was done in conjunction with systematic observation by task analysis. In 


\section{$16^{\circ}$ \\ ERGODESIGN USIHC CINAHPA}

$16^{\circ}$ Ergodesign - Congresso Internacional de Ergonomia e Usabilidade de Interfaces Humano Tecnológica: Produto, Informações Ambientes Construídos e Transporte

$16^{\circ}$ USIHC - Congresso Internacional de Ergonomia e Usabilidade de Interfaces Humano Computador

CINAHPA | 2017 - Congresso Internacional de Ambientes Hipermídia para Aprendizagem.

general, the new version has increase the accept and engagement of users in survey process. Most users has approved the change but the research found several points which need to improve.

\section{Introdução}

A Universidade Federal do Rio Grande do Norte (UFRN), através da Superintendência de Informática (SINFO), desenvolve os sistemas integrados de gestão (SIGs). Um deles, o Sistema Integrado de Gestão de Recursos Humanos (SIGRH), é objeto de estudo deste trabalho.

Através do SIGRH é realizado anualmente o Levantamento de Necessidades de Capacitação (LNC) que possibilita o planejamento e execução de atividades de capacitação para os servidores, no entanto, há relatos de resistência no preenchimento voluntário da ferramenta sendo a quantidade de participações bastante inferior a quantidade de servidores ativos na instituição.

No ano de 2015, a Pró Reitoria de Gestão de Pessoas da UFRN (PROGESP), desenvolveu o projeto de Gamificação. Um dos intuitos do projeto foi obter um maior engajamento dos servidores no Levantamento de Necessidades de Capacitação e assim também obter uma quantidade maior de participações. A gamificação é uma estratégia para engajar os usuários através da aplicação de recursos semelhantes a jogos em contextos não relacionados a jogos. O LNC passou por um completo redesign sendo um projeto piloto de gamificação nos sistemas da UFRN.

O projeto seguiu diretrizes do Design Centrado no Usuário, uma abordagem de desenvolvimento de produtos que envolve o usuário em todas as fases de elaboração do produto diminuindo a possibilidade de problemas de interação e adequando o produto ao usuário. De acordo com a Coordenadoria de Capacitação e Educação Profissional (CCEP), o projeto foi bem-sucedido pois o LNC alcançou um número maior de respostas comparado a anos anteriores, porém ainda abaixo das expectativas.
Este trabalho tem por objetivo analisar os impactos que a mudança realizada no sistema provocou junto ao usuário do sistema, se este a considerou positiva ou não, se problemas existentes na versão anterior foram solucionados e se existem pontos a melhorar na nova versão e responder, qual o nível de influência que a Gamificação e o Design Centrado no Usuário podem ter tido sobre os resultados.

\section{Conceitos Balizadores da Pesquisa}

O Design Centrado no Usuário é uma abordagem aplicada ao desenvolvimento de produtos de sistemas de informação. A aplicação na área de desenvolvimento de sistemas tem sua relevância confirmada pela existência do padrão ISO 9241210 (2010). A norma afirma que sua aplicação melhora a eficácia e eficiência, aumenta o bemestar humano, a satisfação do usuário, acessibilidade e sustentabilidade.

A gamificação (termo originado de um neologismo da língua inglesa - Gamification) significa a utilização de elementos de jogos em contextos distintos de jogos. $\mathrm{O}$ termo gamificação foi criado pelo programador britânico Nick Pelling que o utilizou em 2002 para descrever a proposta de uma interface semelhante à de jogos com o objetivo de facilitar o trabalho de clientes (usuários) em transações eletrônicas (NAVARRO, 2013; BURKE, 2015). O termo, no entanto, foi recebendo novos significados com o passar do tempo e, hoje é uma abordagem de desenvolvimento de interfaces.

Werbach e Hunter (2012) apud Costa e Marchiori (2015) propõem três tipos de elementos de jogos aplicáveis às interfaces: dinâmicas, mecânicas e componentes. As dinâmicas são temas através do 
$16^{\circ}$ Ergodesign - Congresso Internacional de Ergonomia e Usabilidade de Interfaces Humano Tecnológica: Produto, Informações Ambientes Construídos e Transporte

$16^{\circ}$ USIHC - Congresso Internacional de Ergonomia e Usabilidade de Interfaces Humano Computador

CINAHPA | 2017 - Congresso Internacional de Ambientes Hipermídia para Aprendizagem.

qual o jogo se desenvolve - emoções, narrativa, progressão (fases), relacionamentos e restrições; as mecânicas - aquisição de recursos, feedback sobre o desempenho do jogador, chance, desafios, recompensas, turnos (a vez de jogar) e vitórias; Componentes - parte visível do jogo: avatar, bens, combate, missão, etc.

Outro autor sugere ainda o que chama de Elementos Dramáticos: "toda a sua estrutura estética: das cores e formas de objetos, efeitos sonoros e composições musicais, das histórias e seus personagens. " (FULLERTON, 2008 apud BERIMBAU, 2014, p. 11)

\section{Métodos e Técnicas}

A presente pesquisa é um Estudo de Caso sobre o Projeto de Gamificação do LNC. A pesquisa foi dividida em três partes. Na primeira parte, buscouse fazer uma retrospectiva do projeto de gamificação realizando entrevistas com seis participantes do projeto objetivando compreender como o projeto foi estruturado e executado.

$\mathrm{Na}$ segunda parte, foram reunidos dados disponíveis sobre o LNC: relatórios do SIGRH, dados da base de dados do sistema (ex. total de respostas ao formulário). Além disso, foram analisados dois relatórios produzidos pela CCEP, 22 chamados cadastrados pelos usuários durante os períodos de aplicação do LNC na versão antiga e nova, entre outros, objetivando comparar dados anteriores à gamificação e posteriores à gamificação.

A terceira e principal parte visou analisar a percepção do usuário sobre a mudança feita no sistema, buscando conhecer a opinião deste em quesitos que vão desde o novo design do LNC, a satisfação de uso/experiência, comparando a versão antiga (disponível até 2014) e nova (gamificada). Para isso, foi utilizada a técnica de Avaliação Cooperativa e questionário.
De acordo com Monk (1993) apud Santa Rosa (2012), a avaliação cooperativa tem como objetivo obter dados sobre problemas em um sistema a fim de melhorar o produto. Benyon (2011), explica que o nome leva o termo "cooperativa" devido à participação dos usuários como co-avaliadores uma vez que não só navegam pelo sistema, mas podem tecer comentários e questionar.

A Avaliação Cooperativa contou com a participação de 12 usuários (quantidade definida por conveniência) dos perfis típicos que utilizam o sistema: gestores, técnicos-administrativos e docentes, sendo quatro usuários de cada um dos perfis. Além dos perfis típicos, buscou-se dividir os usuários de acordo com alguns critérios: idade, sexo e familiaridade com o LNC. O objetivo foi verificar se havia diferenças de comportamento e percepção relacionados a esses critérios.

Para as sessões de avaliação foram elaboradas listas de tarefas para cada perfil, e para cada versão do sistema. Essas listas guiaram as avaliações, e foram úteis para a observação sistemática por análise da tarefa, técnica que observa o comportamento do usuário durante a realização de uma determinada tarefa, segundo aspectos préestabelecidos.

Foram aplicados, ainda, dois questionários de formato semelhante a um questionário de satisfação (QUIS) (SHNEIDERMAN, 1998). Os dados obtidos através das técnicas utilizadas foram comparados e confrontados e os resultados apresentados.

\section{Resultados}

A seguir são apresentados os resultados da pesquisa, organizados de acordo com cada fase da pesquisa e posteriormente apresentada análise global dos resultados.

\subsection{O Processo De Desenvolvimento Do Novo Lnc - Análise Passo A Passo}




\section{$16^{\circ}$ \\ ERGODESIGN USIHC CINAHPA}

De acordo com as entrevistas com membros das equipes de desenvolvimento percebeu-se como ocorreu o projeto do sistema. É possível notar ênfase no Design Centrado no Usuário e em uma abordagem multidisciplinar que envolveu profissionais com diferentes áreas de expertise $\mathrm{e}$ diversos pontos de vista.

O primeiro passo do projeto foi de responsabilidade do Escritório de Ideias - EI setor inserido da Pró Reitoria de Gestão de Pessoas da UFRN e diretamente envolvido no projeto de Gamificação do LNC - que reuniu a equipe e, seguindo uma rotina do próprio EI, junto com a equipe do projeto, desenvolveu o quadro

CANVAS, um diagrama utilizado para Gestão de Projetos, que continha as variáveis envolvidas. A partir dessa visão, a equipe passou a se reunir semanalmente, durante sete meses, e em cada reunião discutiu como seria o novo formato do LNC com o auxílio de especialistas, gestores e usuários do sistema. Além do brainstorming presente em todas as reuniões, algumas técnicas foram adotadas pela equipe para auxiliar no redesign do LNC.

\subsubsection{Mapa de Empatia}

O mapa de empatia foi uma estratégia utilizada nas reuniões para que os envolvidos no projeto pudessem refletir sobre as necessidades de cada um dos perfis-alvo do LNC: gestores, técnicosadministrativos e docentes. Cada um dos envolvidos preenchia numa folha ideias que os perfis poderiam ter sobre a capacitação e sobre o LNC. As respostas de cada um foram reunidas em um mapa final de cada perfil que serviram para orientar e embasar as decisões dos projetistas a respeito do re-design do sistema.

\subsubsection{Protótipo - WIREFRAME}

Outra estratégia utilizada no processo de $16^{\circ}$ Ergodesign - Congresso Internacional de Ergonomia e Usabilidade de Interfaces Humano Tecnológica: Produto, Informações Ambientes Construídos e Transporte

$16^{\circ}$ USIHC - Congresso Internacional de Ergonomia e Usabilidade de Interfaces Humano Computador

CINAHPA | 2017 - Congresso Internacional de Ambientes Hipermídia para Aprendizagem.

desenvolvimento do LNC gamificado foram os wireframes (esquematizações básicas) com o objetivo de gerar uma visualização aproximada do que seria o produto final. No caso do LNC, era necessário também prototipar em alta-fidelidade para visualizar a proposta de gamificação.

O uso de protótipos faz parte das recomendações do Design Centrado no Usuário (GOULD e LEWIS, 1985) e, para o projeto de gamificação, foi essencial para possibilitar uma visualização do que seria o produto pronto. Santa Rosa (2012, p. 198), afirma que os protótipos servem para “... testar a viabilidade técnica de uma ideia, esclarecer alguns requisitos vagos, realizar testes e avaliações com usuário...".

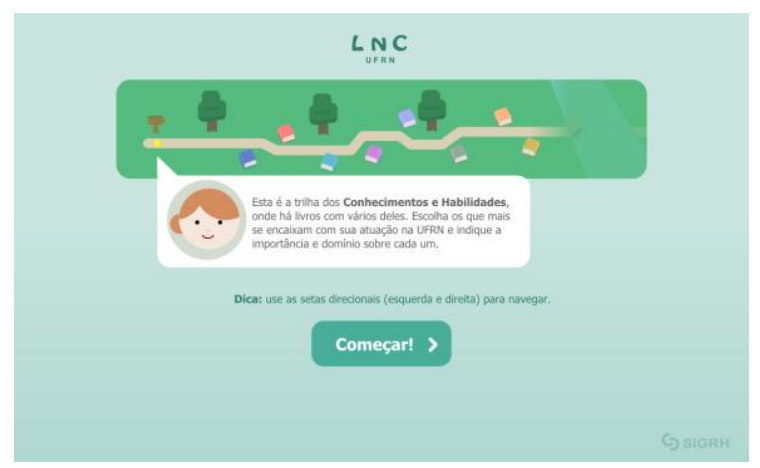

Figura 1 - Wireframe do LNC

\subsection{Análise Do Projeto Quanto Ao Design Centrado No Usuário}

O diagrama CANVAS, criado pelo Escritório de Ideias em conjunto com a equipe, permitiu uma visualização do projeto e de alguns aspectos relacionados a requisitos dos usuários para a nova ferramenta. O levantamento de requisitos é uma das atividades essenciais do DCU segundo a norma ISO 9241-210 citada no texto deste trabalho: a) Levantamento de requisitos (entender e especificar o contexto de uso); b) Especificação de requisitos: especificar os requisitos dos usuários e organizacionais.

Outra diretriz do DCU está vinculada a 


\section{$16^{\circ}$ \\ ERGODESIGN USIHC CINAHPA}

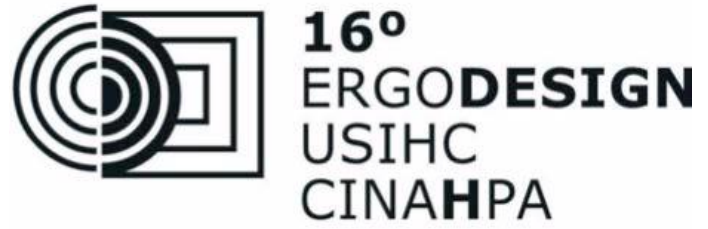

compreensão do contexto de uso, ou seja, o contexto em que o usuário está envolvido quando utiliza o sistema. O Mapa de Empatia é uma estratégia que colabora para a compreensão do contexto de uso e visão do usuário e suas necessidades. Os Mapas de Empatia foram desenvolvidos pela equipe do projeto que contava com usuários de cada um dos perfis. Ele foi desenvolvido no início do projeto para compreender as necessidades do usuário e assim adequar a ferramenta a cada um deles, porém, não tem a mesma eficácia que a entrevista junto ao usuário real pois normalmente algum aspecto deixa de ser citado.

A gamificação foi voltada para a área de negócio interno da UFRN, para engajar servidores (gestores, docentes e técnicos-administrativos) a participar do Levantamento de Necessidades de Capacitação. Com o objetivo de produzir uma nova ferramenta de boa qualidade, buscou-se trabalhar a abordagem de Design Centrado no Usuário através do envolvimento de usuários em todas as etapas do projeto. Alguns desses usuários eram os próprios membros da equipe do projeto de gamificação e outros foram convidados pela equipe para realizar testes na ferramenta. Porém, ao longo da pesquisa foi constatado que dentro de cada perfil, haviam algumas especificidades que o projeto não previu, por exemplo, chefes de departamento - que exercem ao mesmo tempo função de gestor e de docente.

\subsection{Análise da Gamificação Do LNC}

Para diferenciar os perfis-alvo do LNC foram utilizados avatares, ou personagens, um elemento de jogo classificado como Componente de Jogo na gamificação (WERBACH e HUNTER, 2012).

A seguir são listados os elementos e mecânicas de jogos utilizados no LNC [WERBACH e HUNTER 2012; GARTNER, 2016; BURKE, 2015; ZICHERMANN E CUNNINGHAM, 2011 apud KLOCK et al. 2014]: $16^{\circ}$ Ergodesign - Congresso Internacional de Ergonomia e Usabilidade de Interfaces Humano Tecnológica: Produto, Informações Ambientes Construídos e Transporte

$16^{\circ}$ USIHC - Congresso Internacional de Ergonomia e Usabilidade de Interfaces Humano Computador

CINAHPA | 2017 - Congresso Internacional de Ambientes Hipermídia para Aprendizagem.
- Personagens: Embora o LNC apresente uma interface bastante semelhante para os três perfis, os formulários não são iguais e apresentam particularidades relacionadas a cada um dos perfis. Esses perfis podem ser considerados como Personas no DCU e conforme Gould e Lewis (1985) integram um dos princípios básicos do DCU.

- Fases: indicam o progresso do usuário dentro do sistema e podem estar associados a dificuldade do jogo;

- Desafios e missões: motivam os jogadores;

- Integração: inserir uma pessoa nova ou inexperiente no sistema. O sistema deve cativar e encorajar o usuário a permanecer nele;

- Reforço e Feedback: orientação ao usuário, informação sobre sua localização e/ou sobre o seu desempenho atual no jogo;

- Narrativa: história que engaja o usuário no jogo.

Quanto aos elementos de motivação (BURKE, 2015) utilizados, pode-se identificar:

- Autonomia: o formulário é de preenchimento voluntário e o usuário pode optar por preencher ou não a ferramenta;

- Domínio: o usuário tem etapas para concluir e é convidado à uma missão, e na bandeira ao final é colocado como um dos vencedores (concluiu o desafio);

- Propósito: essa parte poderia ser melhor explorada, por exemplo, o usuário poderia ser convidado a promover com sua participação o desenvolvimento institucional da UFRN ao desenvolver seu próprio desempenho como servidor através das atividades de capacitação oferecidas. 


\section{$16^{\circ}$ \\ ERGODESIGN USIHC CINAHPA}

\subsection{Análise Dos Relatórios Produzidos Pela CCEP}

A CCEP produziu e disponibilizou dois relatórios, um com dados da aplicação do LNC em 2014 (17/11/2014 a 02/01/2015) e outro com os resultados obtidos pela versão gamificada da ferramenta (10/12/2015 a 25/04/2016).

O número de respondentes do LNC de 2013/2014 para 2014/2015, subiu 169\%, já em 2016, após a gamificação, o LNC teve um aumento de $287 \%$ em relação ao LNC anterior, quase triplicando a quantidade de respostas.

Através deste mesmo relatório foi verificada também uma preocupação da equipe da CCEP com a opinião do usuário. A equipe promoveu diversas visitas presenciais a setores da universidade com o intuito de compreender as necessidades dos usuários e captar sugestões de melhorias.

Os períodos de 21/08/13 a 27/09/13 e 17/11/14 a 02/01/15 referem-se a versão antiga do LNC e o período de 15/12/15 a 25/04/16 corresponde a versão nova, gamificada, do LNC. Com o auxílio do site: http://www.calendario-365.com.br/ foi possível calcular a quantidade de dias que cada versão do LNC ficou disponível e com base nisso estimar a média de respostas por dia de cada versão, constatando que a média da versão Gamificada se manteve muito aproximada da média de respostas da versão anterior.

- $\quad$ LNC 2013: 318/38 dias $=8,36$ respostas/dia;

- $\quad$ LNC 2014: 538/47 dias $=11,44$ respostas/dia;

- $\quad$ LNC 2015: $1547 / 133$ dias $=11,63$ respostas/dia; $16^{\circ}$ Ergodesign - Congresso Internacional de Ergonomia e Usabilidade de Interfaces Humano Tecnológica: Produto, Informações Ambientes Construídos e Transporte

$16^{\circ}$ USIHC - Congresso Internacional de Ergonomia e Usabilidade de Interfaces Humano Computador

CINAHPA | 2017 - Congresso Internacional de Ambientes Hipermídia para Aprendizagem.

\subsection{Análise Dos Chamados Abertos Pelos Usuários}

O novo LNC foi aplicado em dois calendários: um para os servidores técnico-administrativos e docentes, durante o período de 15 de dezembro de 2015 à 10 de abril de 2016, e outro para os gestores no período de 15 de dezembro de 2015 à 25 de abril de 2016.

Através da ferramenta Iproject, o setor de suporte da SINFO gerencia os chamados, que são solicitações dos usuários do sistema para ajustes e correções de erros com os quais os usuários venham a se deparar ao navegar pelo sistema. Através do Iproject foi possível consultar os chamados abertos durante o período de aplicação do LNC e analisar as principais queixas que demandaram chamados. Também foi possível consultar o mesmo período do ano anterior ao redesign do LNC que antes possuía um mesmo calendário para todos os servidores com ou sem função gerencial.

Embora a quantidade de chamados seja mínima em relação a quantidade de respondentes (apenas 1\% na versão gamificada, por exemplo), podem ser observados alguns dados relevantes em especial na versão gamificada, dados que são analisados a seguir.

Observou-se, de acordo com os resultados, que dos problemas identificados no novo LNC, $75 \%$, ou seja, mais da metade dos chamados, se referem ao usuário estar preso na fase 2 ou 3.

Em alguns momentos nos testes foi percebido que mesmo preenchendo todos os itens o sistema manteve o usuário preso na fase. Ao sair e retornar, quando retornava algumas respostas anteriormente dadas haviam sido apagadas na fase onde exigia que preenchesse todas, ou seja, algum mecanismo do sistema exibiu o preenchimento, mas elas não estavam sendo efetivamente registradas na base, o que provocava o erro. 


\section{$16^{\circ}$ \\ ERGODESIGN USIHC CINAHPA}

$16^{\circ}$ Ergodesign - Congresso Internacional de Ergonomia e Usabilidade de Interfaces Humano Tecnológica: Produto, Informações Ambientes Construídos e Transporte

$16^{\circ}$ USIHC - Congresso Internacional de Ergonomia e Usabilidade de Interfaces Humano Computador

CINAHPA | 2017 - Congresso Internacional de Ambientes Hipermídia para Aprendizagem.

\subsection{Resultados Da Avaliação Cooperativa}

Para organizar os resultados da Avaliação

Cooperativa identificou-se os usuários avaliadores pelas 12 primeiras letras do alfabeto, de $\mathrm{A}$ à $\mathrm{M}$, agrupando por perfil: os gestores de A à D, Figura 2, os técnicos-administrativos de $\mathrm{E}$ à $\mathrm{H}$, e os docentes de I à M. Do perfil gestor foram entrevistados: uma chefe de departamento, um coordenador de curso de pós-graduação, uma próreitora e um chefe de setor.

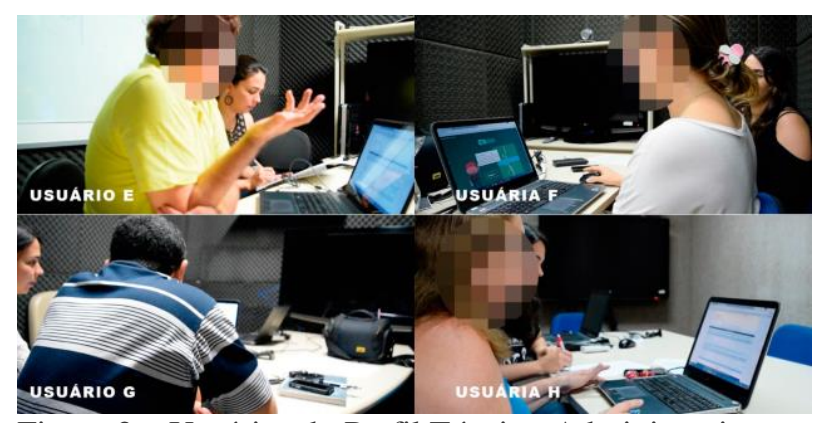

Figura 2 - Usuários do Perfil Técnico-Administrativo Realizando Avaliação Cooperativa

Para melhor compreensão dos resultados encontrados, optou-se por organizá-los, em um primeiro momento, separando a avaliação por versão do formulário, primeiro os resultados da avaliação da versão antiga e depois os resultados da avaliação da versão nova sendo estes agrupados por perfil, em virtude do formulário sofrer modificações de acordo com o perfil do servidor. Os usuários A e B são docentes com função gerencial Chefe de Departamento e Coordenador de Curso. Por esta razão avaliaram o formulário como docente e como gestores, pois era uma exigência na versão antiga do LNC. Da mesma maneira os usuários técnicos administrativos com função gerencial C e D, avaliaram como técnicos e como gestores.

Embora tenha sido utilizada uma lista de tarefas para cada perfil e versão do sistema optou-se, para uma melhor visualização, não descrever os resultados por tarefa, mas sim por tela do formulário. Além disso, optou-se por agrupar os resultados em categorias: Usabilidade (organização das informações,

facilidade/dificuldade na execução de tarefas); Ergonomia Informacional (compreensão dos Símbolos, compreensão da linguagem utilizada); Performance (lentidão, erros); Experiência do Usuário (Reações, percepções e sentimentos ao navegar pela ferramenta); Sugestões (sugestões do usuário).

\subsubsection{Considerações Gerais Sobre a Versão Antiga}

Em relação à Experiência do Usuário, a versão antiga não agrada a totalidade dos usuários sendo considerada cansativa pelo excesso de textos, longa com linguagem prolixa e considerada também complicada de responder. Isso levava o usuário a não responder ou responder de forma descompromissada.

Uma vantagem citada nesse modelo era a escala com 5 itens que é mais comum, o usuário associa a modelos mentais de escalas de cinco pontos.

Sobre a ferramenta, o usuário não vê quais resultados pode trazer para si mesmo. Um dos docentes entrevistados comentou que esse resultado é mais perceptível na avaliação, mas em relação ao LNC ele não sabe como terá retorno sobre os cursos indicados ou sobre as informações que prestou, tornando o instrumento aparentemente sem sentido.

Muitos dos avaliadores ao saberem que iram avaliar o SIGRH já afirmavam que só acessavam o SIGRH para fazer consultas ou marcar férias, portanto, poucas vezes ao ano.

$\mathrm{Na}$ ferramenta antiga o usuário se sente perdido sem noção do que surge a cada nova tela, porque a descrição inicial é vaga.

\subsubsection{Avaliação da Versão Gamificada}




\section{$16^{\circ}$ \\ ERGODESIGN \\ USIHC CINAHPA}

A versão Gamificada da ferramenta objetivou corrigir problemas detectados na versão anterior. Alguns dos problemas citados pelos usuários na avaliação da versão antiga já eram do conhecimento da equipe da CCEP e estão descritos no Relatório produzido por eles da versão de 2014, indicando já haver uma preocupação com o usuário por parte da equipe que idealizou a ferramenta.

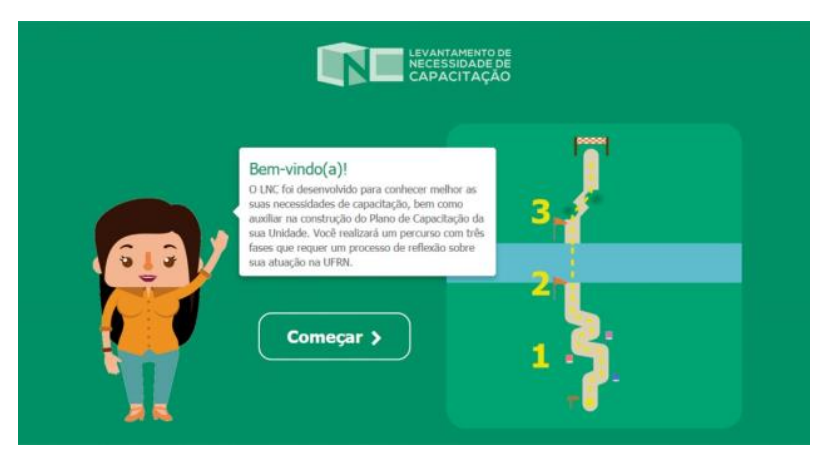

Figura 3 - Tela de Boas Vindas LNC Gamificado

A primeira tela da nova versão era uma tela de boas-vindas com uma breve explicação sobre o LNC. Na tela era exibido um personagem que mudava de acordo com o perfil - docente, gestor, técnico-administrativo como ilustrado na Figura 3.
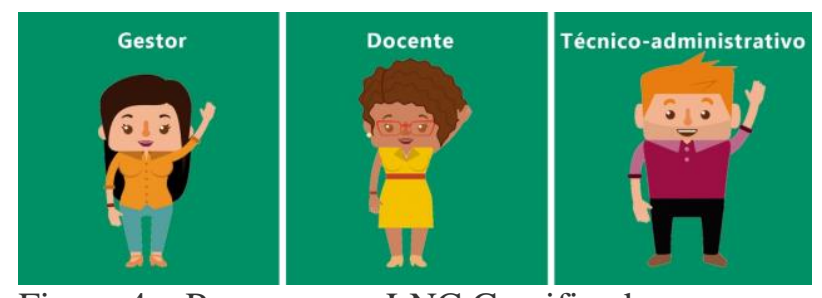

Figura 4 - Personagens LNC Gamificado

A totalidade dos usuários participantes considerou a tela de boas-vindas agradável, explicativa, com passos bem definidos e também que a letra possui um tamanho bom de leitura que não cansa, demonstrando preocupação com o usuário. $16^{\circ}$ Ergodesign - Congresso Internacional de Ergonomia e Usabilidade de Interfaces Humano Tecnológica: Produto, Informações Ambientes Construídos e Transporte

$16^{\circ}$ USIHC - Congresso Internacional de Ergonomia e Usabilidade de Interfaces Humano Computador

CINAHPA | 2017 - Congresso Internacional de Ambientes Hipermídia para Aprendizagem.

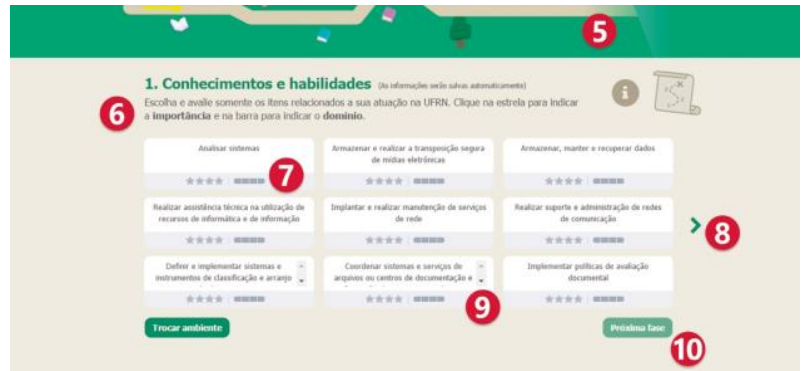

Figura 5 - LNC Gamificado Fase 1 - Tela 2 - Pontos Comentados pelos Usuários
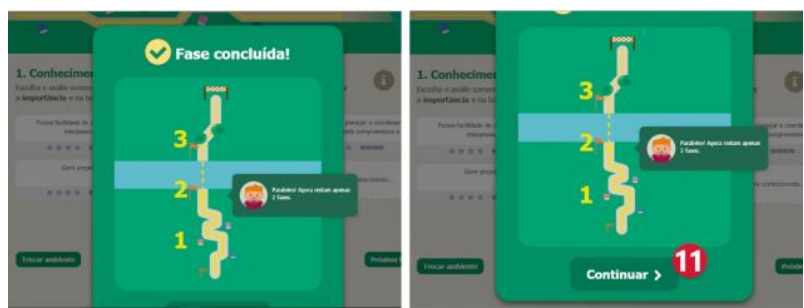

Figura 6 - Conclusão da Fase 1

\subsubsection{Pontos da Versão Antiga Corrigidos na Nova Versão}

A nova versão do LNC foi bem aceita pela totalidade de servidores que participaram da avaliação cooperativa, sendo no aspecto da experiência do usuário considerada muito agradável. Essa versão trouxe solução para pontos problemáticos da versão antiga percebidos pelo usuário que são:

- Textos longos e letra pequena: a nova versão traz explicações em textos curtos em com bom tamanho de letra.;

- Tamanho de formulário e etapas indefinido: a nova versão tem três etapas bem definidas;

- Etapa de preenchimento opcional com campos obrigatórios: os campos não são mais marcados como obrigatórios nas indicações de cursos de educação formal;

- Falta de visão da equipe no formulário do 


\section{$16^{\circ}$ \\ ERGODESIGN USIHC CINAHPA}

gestor: a nova versão traz para o gestor a visão da equipe;

- Preenchimento complicado e trabalhoso: O preenchimento ficou bem mais rápido sem a necessidade de selecionar conhecimentos, habilidades e atitudes relacionados a uma atividade e após pontuar. Na nova versão o usuário avalia domínio e importância de forma objetiva;

- Falta de identificação da categoria no formulário: a nova versão traz a categoria bem identificada nos formulários de gestor e de docente, porém não no de técnicoadministrativo;

- No formulário do gestor não há clareza quanto a quem está sendo avaliado, se o próprio gestor ou se sua equipe: a nova versão traz uma divisão clara da avaliação do gestor da avaliação da equipe;

- Perda das informações: o novo LNC salva automaticamente as informações diferente do LNC anterior onde caso o sistema expirasse, o usuário perdia todo o preenchimento feito.

\subsubsection{Problemas Persistentes da Versão Anterior}

A versão gamificada do $\mathrm{LNC}$, embora bem aceita pela grande maioria dos usuários manteve alguns pontos considerados negativos pelos usuários na versão anterior e outros problemas foram identificados pelos usuários. Porém, muitos dos pontos comentados não são problemas, mas apenas sugestões de melhoria feitas pelos usuários durante a avaliação cooperativa.

O formulário traz ainda muitos itens para avaliar nas fases 1 e 2. Falta melhorar a comunicação com o usuário a respeito das regras do sistema. É confuso para o usuário, por exemplo, saber quando $16^{\circ}$ Ergodesign - Congresso Internacional de Ergonomia e Usabilidade de Interfaces Humano Tecnológica: Produto, Informações Ambientes Construídos e Transporte

$16^{\circ}$ USIHC - Congresso Internacional de Ergonomia e Usabilidade de Interfaces Humano Computador

CINAHPA | 2017 - Congresso Internacional de Ambientes Hipermídia para Aprendizagem. deve avaliar todos os itens e quando apenas alguns. Seria melhor mudar o formato, como sugerido pelo usuário B.

A sigla LNC é vaga para quem não conhece. Alguns usuários ainda consideram o preenchimento longo e muitos questionam avaliar atividades vinculadas a ambiente organizacional e não as atribuições do cargo.

O Ambiente Organizacional continuou sendo solicitado para os servidores da categoria técnicoadministrativo e removido do formulário de gestores e docentes. O conceito é desconhecido pela maioria dos usuários, com exceção daqueles que trabalham na área de RH da PROGESP.

O termo Educação Formal continua sendo utilizado não sendo bem compreendido pela maioria dos usuários.

Uma questão observada também é que alguns usuários gestores têm pessoas subordinadas, mas não tem como gerenciar os dados delas no sistema porque estão lotadas em outra unidade. O usuário $\mathrm{B}$, coordenador de curso, tem um subordinado que no sistema está vinculado a outra unidade e por isso não pode indicar cursos de capacitação para ele pelo LNC.

\subsubsection{Usabilidade}

A localização da ferramenta é um problema. Os usuários não a encontram facilmente dentro do sistema. O banner criado na nova versão do LNC não foi percebido pela metade dos entrevistados durante a avaliação que o confundem com uma propaganda ou aviso, sendo considerado discreto. Alguns usuários (C, E J) sugerem acrescentar movimento ao banner de forma que chame mais atenção.

Outro aprimoramento sugerido seria uma vez preenchido, quando fosse consultar, poder acessar diretamente a fase desejada. Isso foi um problema em especial para os gestores que precisavam 


\section{$16^{\circ}$ \\ ERGODESIGN USIHC CINAHPA}

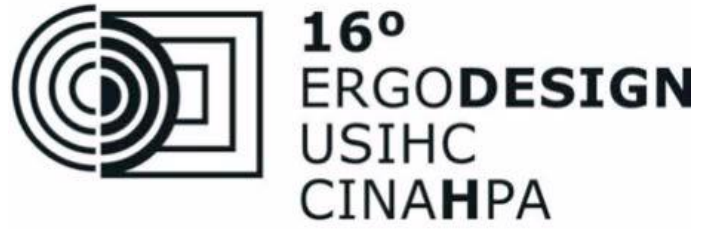

acessar o formulário diversas vezes para validar os cursos escolhidos pela equipe e não tinham como ir direto a fase da equipe tendo que passar por todo formulário.

\subsubsection{Ergonomia Informacional}

Muitos usuários não associam o banner ao LNC, considerando que está pouco chamativo. Percebese a necessidade de fazer com que o sistema se comunique melhor com o usuário a respeito de suas regras. $\mathrm{O}$ usuário $\mathrm{E}$ citou exemplo de uma atendente eletrônica de um serviço de TV que simulava uma pessoas simpática e sugeriu que o sistema deveria fazer o mesmo com instruções como "Você ainda não leu todas as opções, deseja seguir mesmo assim?". A tela deverias ser responsiva. A linguagem deve ser amigável, expressões imperativas soam de forma grosseira "É necessário avaliar todos os itens" a linguagem deve ser mais convidativa.

O usuário não compreende bem o significado de alguns símbolos e desenhos utilizados na interface. "O rio nunca é reto a estrada está mais parecida com um rio do que o próprio rio", foi o comentário de um dos entrevistados que é da área de geologia.

Niemeyer (2003), ao falar sobre a evolução do design ao longo das décadas, destaca que no final do século XX, a significação ganha relevância no desenvolvimento de projetos de sistemas de informação, não bastando uma interface ser agradável (esteticamente) ou funcional, mas também se comunicar adequadamente com o usuário interessado no sistema.

\subsubsection{Experiência do Usuário}

No quesito de Experiência do Usuário, notou-se que a nova versão foi bastante elogiada. E, quando comparada com a versão anterior, os comentários eram muito positivos: "Excelente - muito fácil, intuitivo, tempo de resposta melhor"; "Muito $16^{\circ}$ Ergodesign - Congresso Internacional de Ergonomia e Usabilidade de Interfaces Humano Tecnológica: Produto, Informações Ambientes Construídos e Transporte

$16^{\circ}$ USIHC - Congresso Internacional de Ergonomia e Usabilidade de Interfaces Humano Computador

CINAHPA | 2017 - Congresso Internacional de Ambientes Hipermídia para Aprendizagem. bonitinho"; (A e B); - "Muito legal, estão de parabéns! "; Amigável; (E); "Mil vezes melhor"; Não tem comparação! (E, J, M); Maravilhoso (D).

Uma das avaliações chamou atenção por se tratar de um usuário de 60 anos. O usuário diz que não encontra motivação para preencher a ferramenta e que prefere informação visual, imagens, do que textos longos. Que prefere tentar realizar a operação na base de tentativa e erro do que ler grandes instruções. A ferramenta precisa ser objetiva. De acordo com Mont'Alvão (2000), à medida que as pessoas envelhecem, alguns aspectos físicos e cognitivos mudam, e estas mudanças podem afetar como eles percebem e processam informações e devido a isso notificações e avisos no sistema devem ser mais breves e ter maior legibilidade para estes usuários idosos.

\subsubsection{Performance}

Durante as avaliações foram percebidos alguns erros no sistema e comportamentos fora do padrão. Um deles pode ter sido a causa de alguns chamados que foram abertos durante o período de aplicação do novo LNC. O sistema não permitia ao usuário seguir para a próxima fase mesmo com todas as respostas preenchidas. Verificou-se que ao sair do sistema e retornar algumas respostas dadas haviam sumido o que levou a concluir que para o usuário o sistema mostrava que a resposta tinha sido dada mas o sistema não estava armazenando a resposta na base e por isso não permitia seguir para a próxima fase.

\subsubsection{Questionário com os Participantes da Avaliação Cooperativa}

Dos 12 participantes da avaliação cooperativa, sete já haviam respondido ao LNC alguma vez, sendo que destes apenas quatro já conheciam a versão antiga e três responderam apenas a versão 


\section{$16^{\circ}$ \\ ERGODESIGN USIHC CINAHPA}

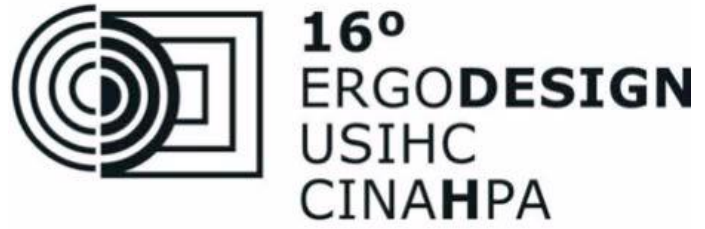

gamificada.

Dentre os cinco que não responderam ao LNC três afirmaram ser por falta de tempo, sendo os três docentes entre eles dois gestores. Os outros dois disseram não ter despertado o interesse ou não compreender do que se tratava a ferramenta, ambos servidores técnicos-administrativos acima de 40 anos.

Sobre o novo LNC, os meios pelos quais os servidores que responderam tomaram conhecimento da ferramenta foram e-mail e Reunião Presencial com Gestores da CCEP, não sendo citado o vídeo de divulgação da ferramenta. As reuniões presenciais são citadas nos relatórios da CCEP e eram reuniões feitas nos setores para captar necessidades dos servidores como também conscientizar sobre a importância da ferramenta.

Dentre os 12 avaliadores, oito servidores afirmaram que a mudança na aparência e estrutura da ferramenta melhorou a sua compreensão sobre a ferramenta. Dentre estes oito, cinco ainda não tinham conhecido a ferramenta.

Os usuários citaram como motivação para preenchimento do LNC principalmente o propósito da ferramenta, por considerarem ser uma ferramenta importante para a UFRN. Apenas um usuário citou a interface nova e moderna como fator motivador para o preenchimento.

Quanto à experiência, todos os usuários consideraram a nova interface melhor e com cores agradáveis, com boas instruções. Além disso, todos consideraram o tour como algo positivo.

Os elementos de jogos percebidos mais citados pelos usuários foram: fases e caminho a percorrer. Apenas dois usuários afirmaram não perceber elementos de jogos, porém ao explicar a todos os usuários quais elementos de jogos haviam na interface, todos afirmaram que estes os estimularam a preencher o LNC.

Apenas três usuários afirmaram nunca ter feito $16^{\circ}$ Ergodesign - Congresso Internacional de Ergonomia e Usabilidade de Interfaces Humano Tecnológica: Produto, Informações Ambientes Construídos e Transporte

$16^{\circ}$ USIHC - Congresso Internacional de Ergonomia e Usabilidade de Interfaces Humano Computador

CINAHPA | 2017 - Congresso Internacional de Ambientes Hipermídia para Aprendizagem. curso de capacitação na UFRN, todos eles docentes.

As sensações experimentadas no preenchimento do novo LNC, mais citadas pelos usuários foram: curiosidade $85,7 \%$; diversão $57,1 \%$; simpatia 57,1/\%; satisfação 57,1\% e bem-estar e impaciência, ambos os últimos com $28,6 \%$ das respostas.

Os diferentes personagens não foram percebidos pela metade dos entrevistados. Os bonequinhos sim.

Sobre a facilidade de preenchimento, $91 \%$ dos usuários consideraram que foi fácil preencher o LNC. Porém, quatro deles consideraram longo ou cansativo, todos do sexo masculino, sendo 3 deles acima de 40 anos.

\section{CONCLUSÃO}

A análise dos dados aponta para muitas questões que não foram percebidas durante a execução do projeto e que evidenciam que alguns princípios do DCU não foram suficientemente ou adequadamente utilizados. Muitas sugestões fornecidas pelos usuários durante a avaliação cooperativa e através do questionário online mostram que a participação do usuário final verdadeiro, e não somente dos gestores que convivem com o usuário, poderia ter evitado lançar um produto final com problemas.

É necessário adicionar na prática do desenvolvimento de software a noção de como o usuário vai interagir com o sistema, refletir sobre as percepções do usuário, trazer o usuário para dentro do processo de desenvolvimento do início ao fim, entender suas características, suas motivações e sentimentos.

\section{BIBLIOGRAFIA}

BERIMBAU, Mauro M. R. Gamificação: Uma 


\section{$16^{\circ}$ \\ ERGODESIGN USIHC CINAHPA}

proposta de desenvolvimento baseada no Game Design com enfoque em comunicação. Disponível em:

$<$ http://www.abciber.org.br/simposio2014/anais/GT s/mauro_miguel_rodrigues_berimbau_160.pdf> Acesso em: 13 out 2016.

BURKE, Brian. Gamificar: como a gamificação motiva as pessoas a fazerem coisas extraordinárias. São Paulo: DVS Editora, 2015.

COSTA, Amanda Cristina Santos; MARCHIORI, Patrícia Zeni. Gamificação, elementos de jogos e estratégia: uma matriz de referência. InCID:

Revista de Ciência da Informação e

Documentação, v. 6, p. 44-65, 2015.

GARTNER GROUP. Gamification. Disponível em: $<\mathrm{http} / / / \mathrm{www}$.gartner.com/it-glossary/gamification2>. Acesso em: 14 out. 2016.

GOULD, J. and LEWIS, C. (1985). Designing for usability: henry ledgard editor key principles and what designers think. Communications of the ACM, 28 (3), 300-311.

GRASSI, Nicholas Bruggner. A gamificação com recurso estratégico para interatividade entre mídias digitais e usuários. Disponível em:

<http://repositorio.unesp.br/bitstream/handle/1144 9/136424/grassi_nb_me_bauru.pdf?sequence=3 > Acesso em: 12 set. 2016.

ISO 9241-210:2010, Ergonomics of human-system interaction -- Part 210: Human-centred design for interactive systems. Disponível em: <

http://www.iso.org/iso/home/store/catalogue_ics/ca talogue_detail_ics.htm?csnumber $=52075>$. Acesso em: 21 jul. 2016.

KLOCK, Ana Carolina Tomé; CUNHA, Lucas Felipe da; GASPARINI, Isabela. Um modelo conceitual para a gamificação de ambientes virtuais de aprendizagem. v. 13, n. 1, 2015. Disponível em: < http://seer.ufrgs.br/index.php/renote/article/view/5 7654/34620 >. Acesso em: 09 out. 2016. $16^{\circ}$ Ergodesign - Congresso Internacional de Ergonomia e Usabilidade de Interfaces Humano Tecnológica: Produto, Informações Ambientes Construídos e Transporte

$16^{\circ}$ USIHC - Congresso Internacional de Ergonomia e Usabilidade de Interfaces Humano Computador

CINAHPA | 2017 - Congresso Internacional de Ambientes Hipermídia para Aprendizagem.
KLOCK, Ana Carolina Tomé; CARVALHO, Mayco Farias de; ROSA, Bryan Eduardo; GASPARINI, Isabela. Análise das técnicas de gamificação em ambientes virtuais de aprendizagem. Revista Renote, ISSN 1679-1916, v. 12, n. 2, 2014 Disponível em: < http://seer.ufrgs.br/index.php/renote/article/view/5 3496> Acesso em: 12 out 2016.

MONT'ALVÃO, Claudia; DAMAZIO, Vera (Org.). Design ergonomia emoção. Rio de Janeiro: Mauad X: FAPERJ, 2008.

NAVARRO, Gabrielle. Gamificação: a transformação do conceito do termo jogo no contexto da pós-modernidade. Biblioteca LatinoAmericana de Cultura e Comunicação, v. 1, n. 1, 2013. Disponível em: <

http://myrtus.uspnet.usp.br/celacc/sites/default/file s/media/tcc/578-1589-1-PB.pdf >. Acesso em: 14 set. 2016.

NIEMEYER, Lucy. Elementos de semiótica aplicados ao design. Rio de Janeiro: 2AB, 2003.

NORMAN, Donald A. O design do dia-a-dia. Rio de Janeiro: Rocco, 2006.

SANTA ROSA, José Guilherme. Ergotrip design: investigação e reflexões sobre design, usabilidade e ergonomia. Rio de Janeiro: Rio Book's, 2014.

SANTA ROSA, José Guilherme, MORAES, Anamaria de. Avaliação e projeto no design de interfaces. 2 ed. Teresópolis-RJ: 2AB, 2012.

SHNEIDERMAN, Ben. Designing the user interface: strategies for effective human-computerinteraction. 3.ed. Reading: Addison Wesley Longman, 1998. $639 \mathrm{p}$.

WERBACH, K.; HUNTER, D. For the win: how game thinking can revolutionize your business. Philadelphia: Wharton Digital Press, 2012.

WERBACH, Kevin. 2013. Disponível em: $<$ http://www.fintraininginnovations.com/presentati ons/march2013/Kevin\%20Werbach.pdf>. Acesso 


\section{$16^{\circ}$ \\ ERGODESIGN \\ USIHC CINAHPA}

$16^{\circ}$ Ergodesign - Congresso Internacional de Ergonomia e Usabilidade de Interfaces Humano Tecnológica: Produto, Informações Ambientes Construídos e Transporte

$16^{\circ}$ USIHC - Congresso Internacional de Ergonomia e Usabilidade de Interfaces Humano Computador

CINAHPA | 2017 - Congresso Internacional de Ambientes Hipermídia para Aprendizagem.

em: 18 out. 2016.

ZICHERMANN, G.; CUNNINGHAM, C.

Gamification by Design: Implementing game

mechanics in web and mobile apps. Sebastopol:

O'Reilly Media Inc, 2011. 